\title{
The Unique Comet Impact Pattern with Reference to Southern Tibet
}

\author{
Mahesh U. Patil \\ Thane, India \\ Email: mup124@rediffmail.com
}

How to cite this paper: Patil, M.U. (2019) The Unique Comet Impact Pattern with Reference to Southern Tibet. Open Journal of Geology, 9, 861-872.

https://doi.org/10.4236/ojg.2019.911095

Received: June 24, 2019

Accepted: October 22, 2019

Published: October 25, 2019

Copyright (C 2019 by author(s) and Scientific Research Publishing Inc. This work is licensed under the Creative Commons Attribution International License (CC BY 4.0).

http://creativecommons.org/licenses/by/4.0/

\begin{abstract}
In the terrestrial planet zone, Comets start outgassing due to solar radiation. This can make comet composition fragile enough to break under the gravitational gradient. Examples like those of Comet Shoemaker-Levy 9 [1] show that it is not unusual for comets to disintegrate due to gravitational gradients. In the event of an impact of such a disintegrated comet on earth, multiple coherent impact craters will be distributed over a large area. The low-density porous composition of the comet will result in the formation of "large flat-floored craters" spread over a large area with a network of faults and fractures as described by Roddy and co-workers (Roddy, 1976; Roddy et al., 1977) [2] [3]. Due to its unusual appearance these impacts patterns are different than rock/metal asteroid impact craters. As a result, these sites are difficult to identify. There are multiple such sites on the planet earth which are under study for impact but due to complex nature of comet impact craters, they have been a conundrum for some time. One such possible site matching the comet impact features can be observed in the southern Tibet between the latitudes of $82^{\circ} 30^{\prime} \mathrm{E}$ and $90^{\circ} 30^{\prime} \mathrm{E}$ and $29^{\circ} \mathrm{N}$ and $33^{\circ} \mathrm{N}$. This study indicates that the lakes in this region were formed by the impact of a single disintegrating comet that hit the region. Observation indicates that the lakes are unusually closely aligned and have a steep slope facing circular feature on the eastern side. Fractures and faults connecting these lakes can be observed over entire subject site hinting towards the multiple impact craters. These craters are large flat-floored and spread over a large area. Gravitational anomaly in the lake region along with the presence of Ultra High Pressure (UHP) minerals like cubic Born Nitride, micro-diamond with the inclusion of Platinum Group Elements (PGE), coesite, Stishovite, osbornite and other complex finds in the region support the possibility of impact.
\end{abstract}

\section{Keywords}

Comet Impact, Micro-Diamond, Tibet Lake, Tektites, Qingsongite, Boron Nitride, 


\section{Introduction}

Tibet has several types of lakes, some of them are freshwater wherein some are saline or saltwater lakes. For formation of these lakes, multiple theories like the plate tectonics, glacial activity are proposed, however it's a complex network that cannot be justified under a single theory. In this study, we propose that the lakes between the latitudes of $82^{\circ} 30^{\prime} \mathrm{E}$ and $90^{\circ} 30^{\prime} \mathrm{E}$ and $29^{\circ} \mathrm{N}$ and $33^{\circ} \mathrm{N}$ are formed by the disintegrated comet impact. The studies on micro-diamond and other UHP minerals conducted by 1) Professor Qing Song Fang et al. (2007) of The Institute of Geology, Beijing-China [4]; 2) Dr. Larissa Dobrzhinetskaya et al. (2006) - The University of California [5] have suggested the possibility of impact in the region.

On the surface of the earth 190 impact craters are listed in the "database of the Planetary and Space Science Centre University of New Brunswick, Canada" [6]. They are typically marked by a mountain in the leading edge of the impact crater. However many impact sites are yet to be discovered because of multiple factors which are present on earth.

The impact is controlled by two factors one is our atmosphere which acts as a shield and hence most of the meteorites vaporize in the atmosphere before they could touch the ground and second critical factor is composition and size of the impacting object, which will define the impact pattern and intensity. Earth has come across impacts from asteroids and comets. The Comet impacts are different from asteroid impacts.

\subsection{Proposed Comet Entry and Impact Pattern}

The Comet goes around the sun in highly elliptical orbit and rarely comes close to earth. Most of the time Jupiter's gravity deflects comets from Oort cloud and Kuiper belt away from the inner planetary system but sometimes it also deflects them towards inner solar system. Such comets can undergo change of orbit and spend more time in inner planetary system. As a result they are exposed to radiation and gravitational gradient making them fragile (Figure 1). Examples like those of Comet Shoemaker Levy 9 [1], comet $72 \mathrm{P}$ and $332 \mathrm{P}$ (Figure 2) show that it is not unusual for comets to break up into multiple pieces due to gravitational gradients and radiation. Impact of such nature would, therefore, creates a series of impressions on the ground. The known comet impact of Sahara desert show desert glass spread over 6000 sq.km. is possibly because of similar entry and impact pattern.

Figure 1 Comet disintegration due to radiation and gravitational gradient it's an artistic presentation by author and not as per actual scale.

Effects of Radiation and Gravity on Comet 
Stage 1: Comet Deflected By Jupiter's Gravity

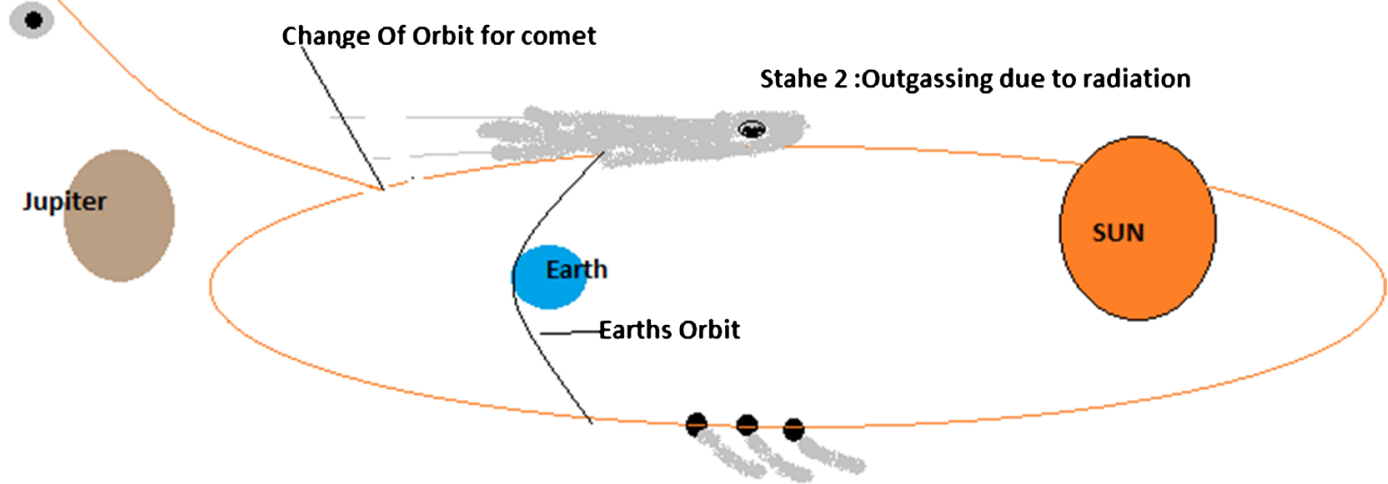

Stage 3 : Disintegration due to radiation and gravitaional gradiant

Figure 1. Orbit of comet deflected by Jupiter and effects of radiation and gravity.

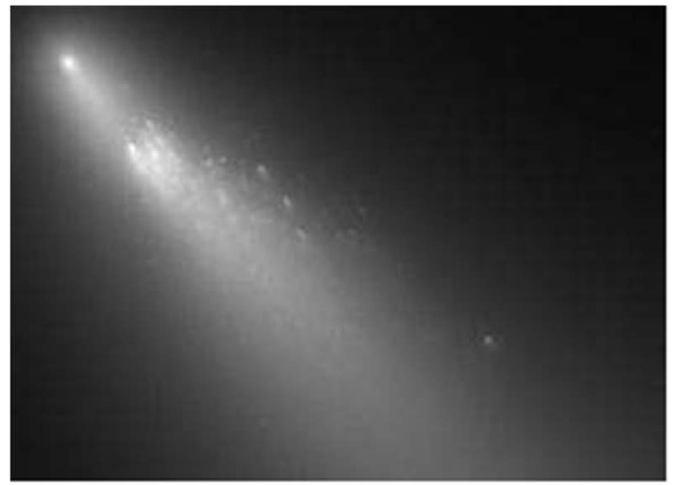

(A)

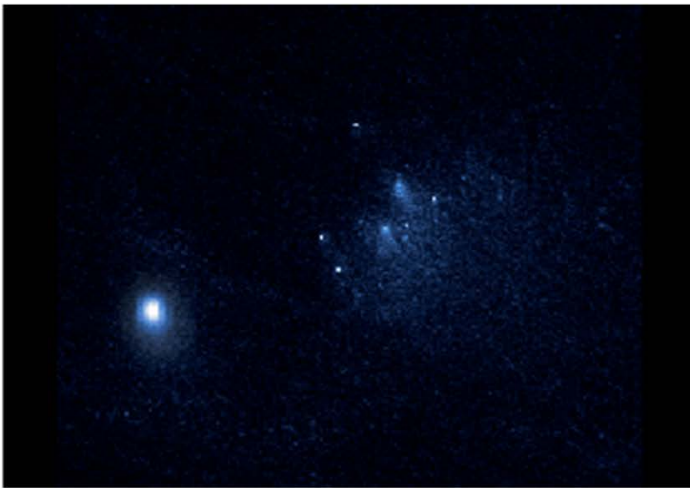

(B)

Figure 2. Comet disintegration of $73 \mathrm{P}$ and $332 \mathrm{P}$. (A) 73 p image source: NASA/ESA/JHU-APL/STScI; (B) 332 p image source Hubblesite.org.

\subsection{Comet Impact Craters}

Comet Nuclei range from a few hundred meters to tens of kilometers across and are composed of loose collections of ice, dust, and small rocky particles. This Initial Density of comet plays a crucial role in the resulting crater shape. Prof. Roddy and others conducted study "High explosive cratering analogs for bowl-shaped, central uplift, and multi ring impact craters" in which they have elaborated snowball craters along with Flynn creek crater (Figure 3). Key findings Of Snowball Impact Crater by J. Roddy [2] [3]

- Crater Was filled with water.

- A wide, shallow bowl-shape flat floor crater interrupted by prominent central uplift.

- Central uplift consisted of several connected mounds of irregularly uplifted clay beds.

- Concentric ring fractures developed in the rim due to differential motion.

- Entire rim near central wall was irregularly depressed and contain many nearly horizontal thrust faults. 


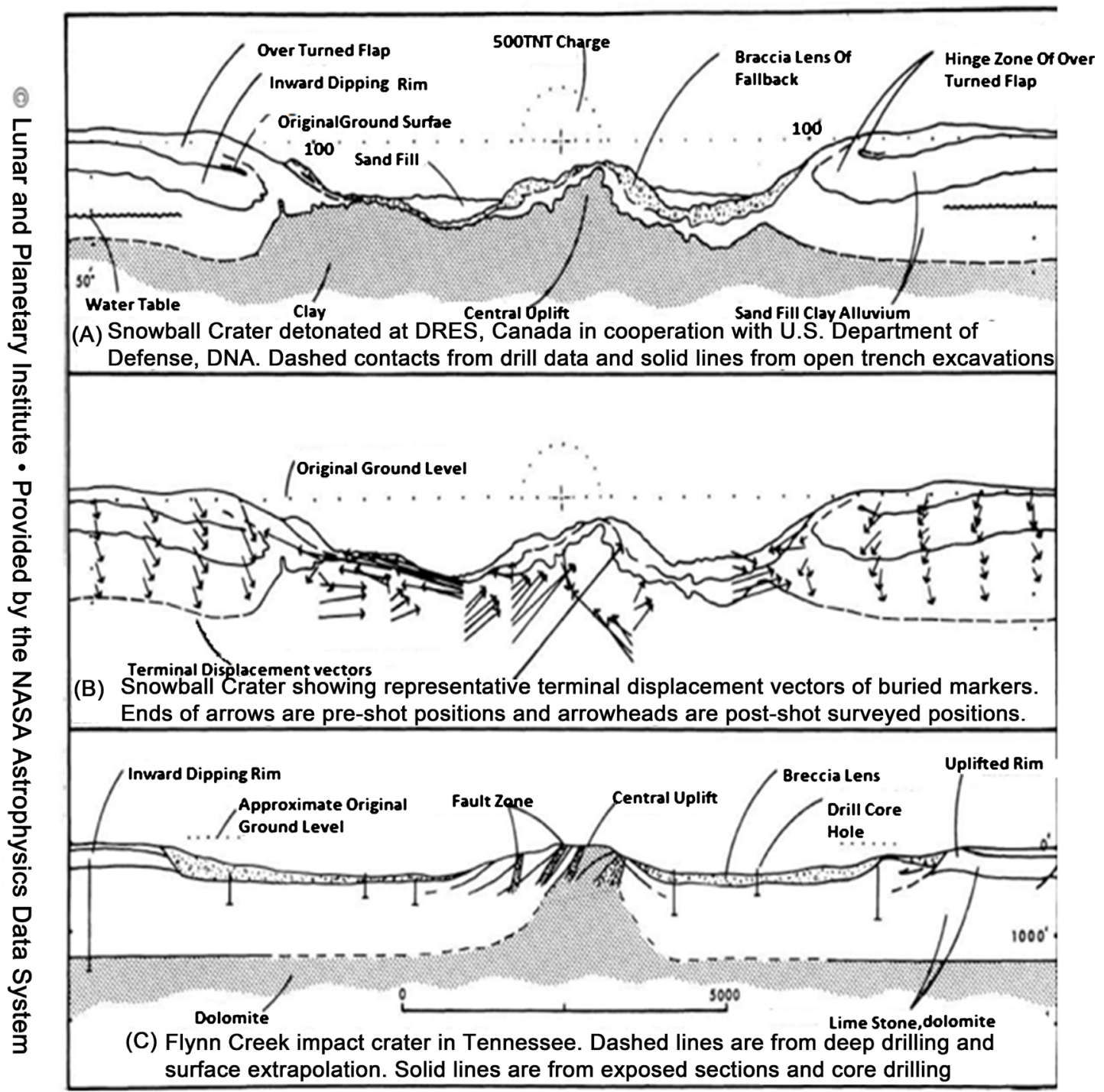

Figure 3. Snowball crater experiment and Flynn creek impact crater. Source: Impact, explosive and nuclear Cratering Mechanics Prof. Roddy D.J.

\subsection{Unique Features of Comet Impact}

Due to disintegration on the path and low density porous nature of impacting material comet impact lead to a unique pattern which is spread over a large area with multiple "wide, shallow bowl-shape flat floor craters". These craters are filled with water resembling to large lakes/dry lakes with interconnecting network of faults and fractures. This results in to network or rivers and canals. These craters due to their unique features are difficult to identify compare to craters formed by rocky/metal asteroids (Figure 4). Such impact sits are rich in complex alloys and ultra high pressure minerals.

\section{Data on Proposed Tibet Impact}

1) UHP Minerals Of Tibet; 2) Tektite; 3) Lakes Features and Gravitational Anomaly; 4) Circumstantial evidence. 
Impact Pattern of Disintegrated Comet vs Asteroid

\begin{tabular}{lll}
\hline Factor & Comet & Asteroid \\
\hline $\begin{array}{l}\text { Radiation and } \\
\text { Gravity (Figure 1) }\end{array}$ & $\begin{array}{l}\text { Due to radiation comet starts out gassing and } \\
\text { become fragile as a result it can break under } \\
\text { Gravitational gradient before it enters the } \\
\text { atmosphere, hence each fragment enter over a } \\
\text { period of time }\end{array}$ & $\begin{array}{l}\text { Most of the time It remains } \\
\text { un affected hence enter as } \\
\text { one unit }\end{array}$ \\
Earths Atmosphere & $\begin{array}{l}\text { Comet has its own atmosphere hence its nuclei } \\
\text { may not come in direct friction hence may not } \\
\text { burst in the air }\end{array}$ & $\begin{array}{l}\text { Small asteroids may } \\
\text { air/large rocky and metal } \\
\text { Result }\end{array}$
\end{tabular}

Figure 4. (A) Comet Impact pattern (Shoemaker Vyas Pattern); (B) Asteroid pattern.

\subsection{UHP Minerals of Tibet}

Comet nuclei are composed of an amalgamation of rock, dust, water ice, frozen carbon dioxide, carbon monoxide, methane, and ammonia. In addition to these gases the nuclei also contain a variety of organic compounds, which may include methanol, hydrogen cyanide, formaldehyde, ethanol, and ethane and perhaps more complex molecules such as long-chain hydrocarbons and amino acids. As a result in the event of impact of such body there is a strong possibility of complex alloy formation.

\section{1) Qinsongite and its origin ( $\mathrm{BN})$}

$$
\mathrm{H}_{3} \mathrm{BO}_{3}+\mathrm{NH}_{3} \stackrel{\Delta}{\longrightarrow} \mathrm{BN}+3 \mathrm{H}_{2} \mathrm{O} \text {. }
$$

a) $\mathrm{H}_{3} \mathrm{BO}_{3}$ : Natural Resource at Tibet

b) $\mathrm{NH}_{3}$ : Part of Comet composition

c) High Temperature\& Pressure: Result of Impact

In 2013 International Mineralogical Association Recognized it as only known boron mineral formed in the deep earth mantle found in Luobusha ophiolite of Tibet autonomous Region in China (Table 1). Boron is rare in the universe, it is formed in minor amounts in cosmic ray spallation and may be found in cosmic dust or meteoroid. Boron is a rare element in the earth crust $(0.001 \%)$ however it can be highly concentrated by the action of water thus it is found in compounds such as borax, boric acid. Tibet lake region is rich source of borax.

Ammonia is a part of Comet composition, hence in the event of comet impact When Boric acid reacts with ammonia at high temperature and UHP above 10 GPa it can form cubic boron nitride. Impact of such nature will lead to transformation of silica and other elements leading to formation of quartz and other complex alloys. 
Table 1. Cubic boron nitride (Qingsongite) properties reaction for formation of BN can be depicted as.

\begin{tabular}{cc}
\hline Formula & $\mathrm{BN}$ \\
\hline Crystal System & Cubic \\
Pressure & $>10 \mathrm{GPa}$ \\
Temperature & Approximately 2400 degree Fahrenheit \\
Associated Minerals & Osbornite (TiN), Coesite, Kyanite, Micro diamond with Os, Ir inclusion \\
Occurrence & Luobusa Ophiolite-Tibet \\
\hline
\end{tabular}

Qingsongite is found in crystal in association with osbornite, Coesite, micro diamond and $\mathrm{Ti}$ rich Kyanite. If we look at the associated minerals that are found with "Qingsongite" then most of these minerals are known for their presence at impact sites. For mantle origin all these elements will require different conditions in the deep earth mantle hence it will be rare possibility that they are found in single crystal. Thus they have undergone the transformation on the surface itself indicating towards UHP impact in its formation. All these minerals are found in placer deposits which again indicate towards the shallow origin.

\section{Associated Minerals with c-BN (Qingsongite) and Impact Origin}

a) Osbornite (TiN): Formed in the star dust and now almost exclusively found in meteorites.

b) Micro Diamonds in Os, Ir inclusion: Fang et al. (2007) [4] and Yang J., Larissa Dobrzhinetskaya et al. (2006) [5] indicate towards the possibility of impact origin of these diamonds.

c) Coesite: Again a common finding at impact sites.

d) Ti rich Kyanite: Ti-rich Kyanite is a unique finding in Tibetan region Mr. Fang's [4] study reveals that Ti presence in kyanite varies from (1.98 wt.\%o 11.64 wt.\%o). Analysis of dust of comet 81/P wild 2 [7] confirms the presence of $\mathrm{Ti}$ in the comet. Hence Kyanite association with Ti must be reviewed from the impact perspective.

\section{2) Boron Carbide}

Boron carbide is a specially hard material in the group of technical ceramics. This is not naturally available on earth. However this has been reported from Tibet Ophiolite along with osbornite, coesite, microdiamond and cBN. Boron carbide can be produced by using following reaction at temperature in the range of $1300^{\circ} \mathrm{C}-1400^{\circ} \mathrm{C}$.

a) $4 \mathrm{H}_{3} \mathrm{BO}_{3} \stackrel{\Delta}{\longrightarrow} 2 \mathrm{~B}_{2} \mathrm{O}_{3}+6 \mathrm{H}_{2} \mathrm{O}$

b) $\mathrm{B}_{2} \mathrm{O}_{3}+3 \mathrm{CO}=2 \mathrm{~B}+3 \mathrm{CO}_{2}$

c) $4 \mathrm{~B}+\mathrm{C}=\mathrm{B} 4 \mathrm{C}$

$\mathrm{H}_{3} \mathrm{BO}_{3}$ : Borax is naturally available in Tibet lake region which is main source for boric acid.

CO: Solid Carbon Monoxide has been reported from comets. Halley's comet had 15\% CO, Ref. Sekanin (1991) [8].

3) Osbornite ( $\mathrm{TiN})$, Ti rich Kyanite and $\mathrm{TiO}_{2} \mathrm{II}$

Osbornite is very rare natural nitride, originally formed in star dust and now 
almost exclusively found in meteorites. TiN has been reported from Tibet Ophiolite as natural origin however it provides no explanation on this rare occurrence and coexistence in a crystal which has most of the finds like coesite after stishovite, microdiamonds with OsIr inclusion which are known for impact origin. The study of star dust from Comet 81P/wild 2 [7] confirm the presence of Ti and osbornite (TiN) in comets. This also simplifies exceptional association of $\mathrm{Ti}$ rich kyanite reported by Fang et al. (2007) [4] with Raman peak reading not matching any known natural mineral or melt. $\mathrm{TiO}_{2} \mathrm{II}$ again is an indicator of either ultra high-pressure or shock induced environment with the temperature in the range of $500^{\circ} \mathrm{C}-1200^{\circ} \mathrm{C}$ and pressure $4-9 \mathrm{Gpa}$ in the formation process. $\mathrm{TiO}_{2} \mathrm{II}$ was first reported from Ries crater Germany. All these finds are strong indicator of impact in the formation.

\section{4) Micro-Diamonds and Other Minerals}

Microdiamonds along with coesite after stishovite, reported from placer deposits of Yarlungzangbo region of Tibetan Ophiolite. These samples have shallow origin. These microdiamonds have OsIr inclusion which is a common feature in the impact event. In nature Stishovites are formed at very high shock pressure close to $10 \mathrm{GPa}$ and temperature in excess of $1200^{\circ} \mathrm{C}$, present during the hypervelocity meteorite impact. Minerals like $\mathrm{Cr}_{2} \mathrm{O}_{3}$ and $\mathrm{FeO}$ in the chromitite again strengthen the possibility of impact.

Such impact on land will allow UHP phase to have overprinted on the lithosphere. Very high temperature of impact event followed by rapid cooling would lead to encapsulation of the minerals within chromitite resulting in low oxygen fugacity of the material. This also explains the perfect preservation of the coesite as a consequence of such rapid cooling after shock as predicated by Fang et al. (2007) [4].

\subsection{Tektites: Tektites Have Been Reported from Various Parts of Asia and Tibet (Indochinites)}

Comet Impacts are high velocity impacts and can lead to tektite formation a small glassy aerodynamical dusty earth material, which is thrown outward from the earth as ejecta by an impact and re arrive on earth after travelling through the atmosphere on their ballistic trajectory. As on date, it is believed that Indochinites are of Australian Strewn field, however, no impact crater has been identified. Australian Tektites are concentrated in southern Australia hence neither plate tectonics, nor ocean current can explain their presence in places like Laos, Vietnam. Impact in Tibet can explain Indochinites. Hence these Tektites may have resulted from Independent strewn, possibly from Tibet (Figure 5).

\subsection{Lakes Features and Gravitational Anomaly in the Lake Region}

We identify a region between $82^{\circ} 30^{\prime} \mathrm{E}$ and $90^{\circ} 30^{\prime} \mathrm{E}$ and $29^{\circ} \mathrm{N}$ and $33^{\circ} \mathrm{N}$ in southern Tibet (Figure 6). The top panel shows the region of Tibet studied here. The second panel shows the lake region marked in Figure 6. The third panel shows the marking of each lake in the region. As can be seen from the figure, the craters seem to be roughly aligned. Gravitational Anomalies are observed in the 


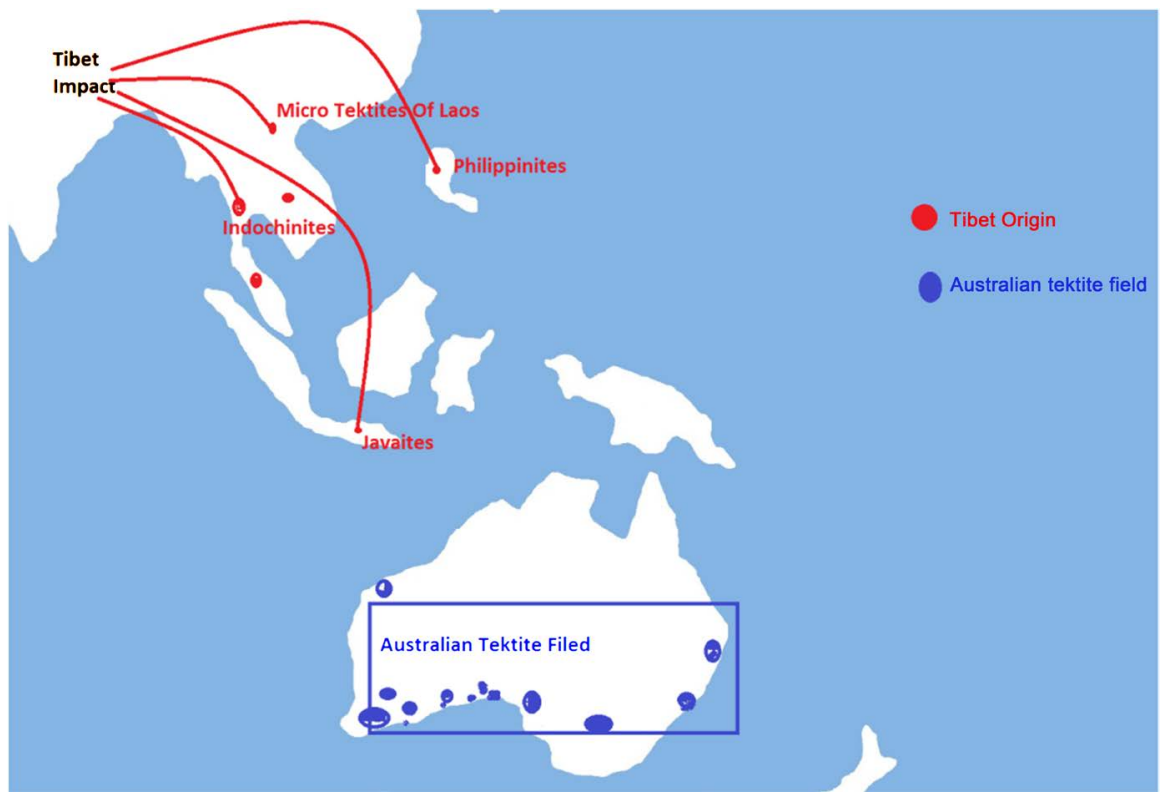

Figure 5. Red Circle Indochinites and Tibetites possible independent strewn from Australian strewn. Reference: Known Tektite Strewn Fields and Finds from McCall (2005) [9] D11.

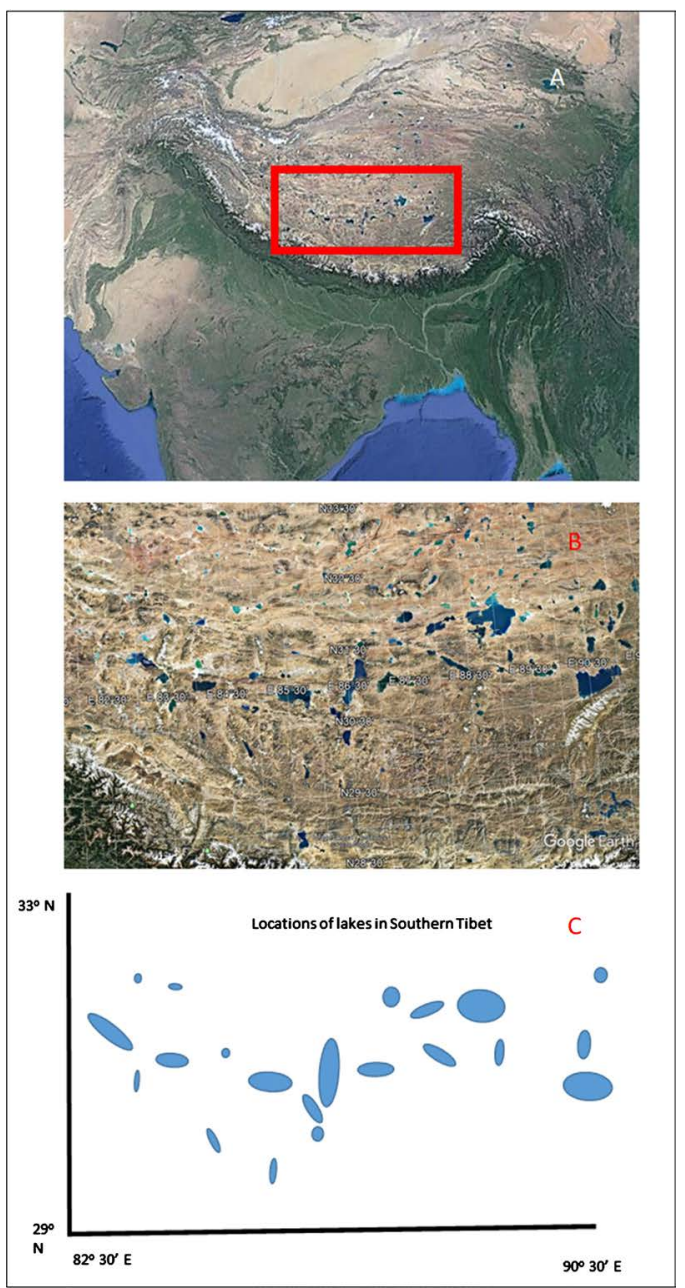

Figure 6. (A) Region of Tibet; (B) Lake Region; (C) Marking of Each Lake. 
same lake region $\left(82^{\circ} 30^{\prime} \mathrm{E}, 29^{\circ} \mathrm{N}\right.$ and $90^{\circ} 30^{\prime} \mathrm{E}, 33^{\circ} \mathrm{N}$ ) gravity anomaly (Figure 7 ). In the event of Impact such anomalies are common. Hence it will be prudent to study this in detail to confirm the findings.

\section{Lake Characteristics (Based on Google Map Images)}

1) These lakes are formed in a straight line creating the resemblance of geometric time impact.

2) These Lakes have 2 - 90 meter of depth.

3) Steep Slope facing circular feature.

4) Small lakes have crater-like appearance (created by angular impact).

5) Large lakes appear to be a combination of two or three water bodies/craters.

6) Fractures and fault lines interconnecting these lakes hinting towards impact that cracked the whole surface.

\subsection{Circumstantial Evidence in the Subject Site (Based on Google Map Images)}

Industrial units near the origin of rivers starting from these lakes indicate alluvial/Placer mining activity (Figure 8). More than 30 such units near lakes can be seen on the satellite map (Google Map) with connecting road network (S205, $301,302)$. This is a remote and inhabitable region thus operating such heavy industry supported by infrastructure indicate towards the large commercial interest in the lake region, hence lake region is the possible source of commercially important minerals. It will be prudent to collect the sample from this region to verify UHP impact instead of Yarlung-Zangbo Suture Zone (Figure 9).

Blue Flag: Industry/Placer mine

Green Box: Sample collection zone of earlier Studies

Sample collection zone (Yarlung Zangbo Region) approximately $200 \mathrm{~km}$ away from the proposed craters possible reason of non-evidence of Impact till date.
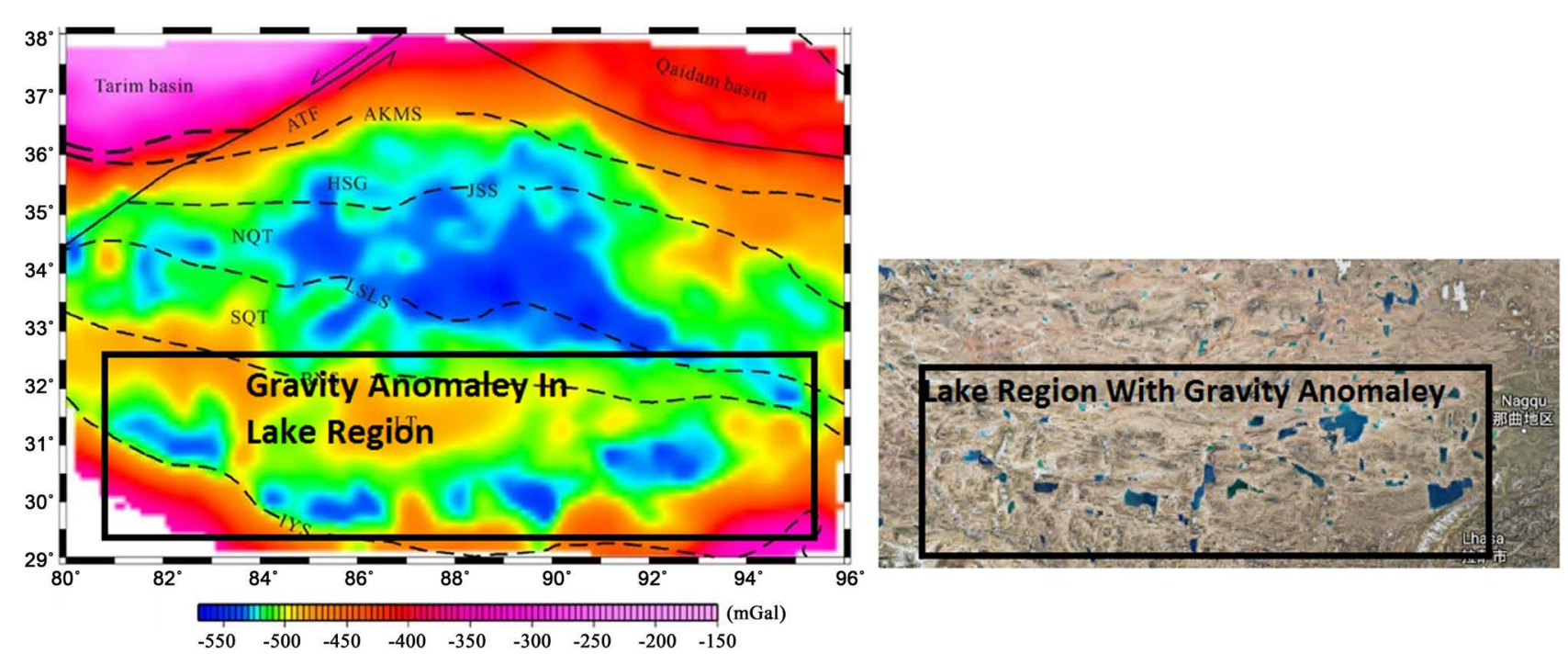

Figure 7. Gravitational anomaly in lake region, Image source: Research gate. 


\section{Other Possible Sites of Comet Impact and "Shallow Bowl-Shape Flat Floor Crater"}

Libya Desert Glass zone Andrew Fazeka [10] and Southern Australia have similar impact patterns with network of lakes and dry lakes. Many of the features resemble to shallow bowl-shape flat floor crater (Figure 10). These regions are

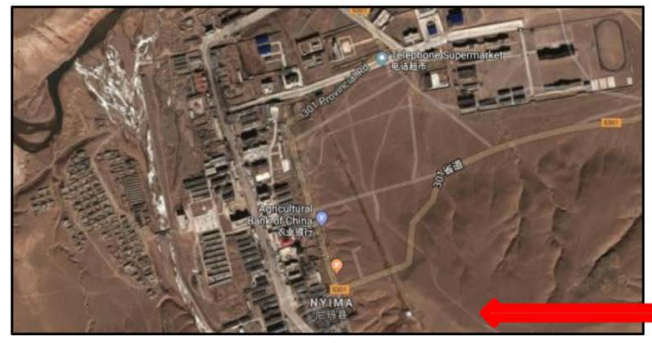

(A)

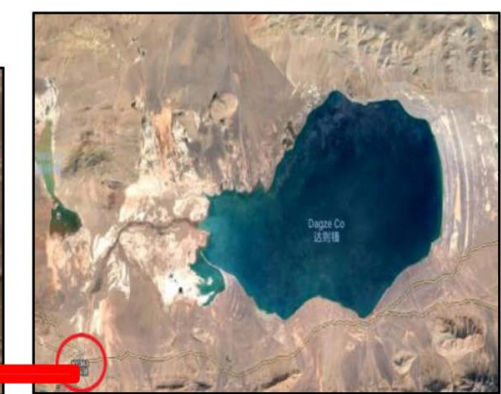

(B)

Figure 8. (A) Industrial/Mining activity on River; (B) Lake Dagze Co.

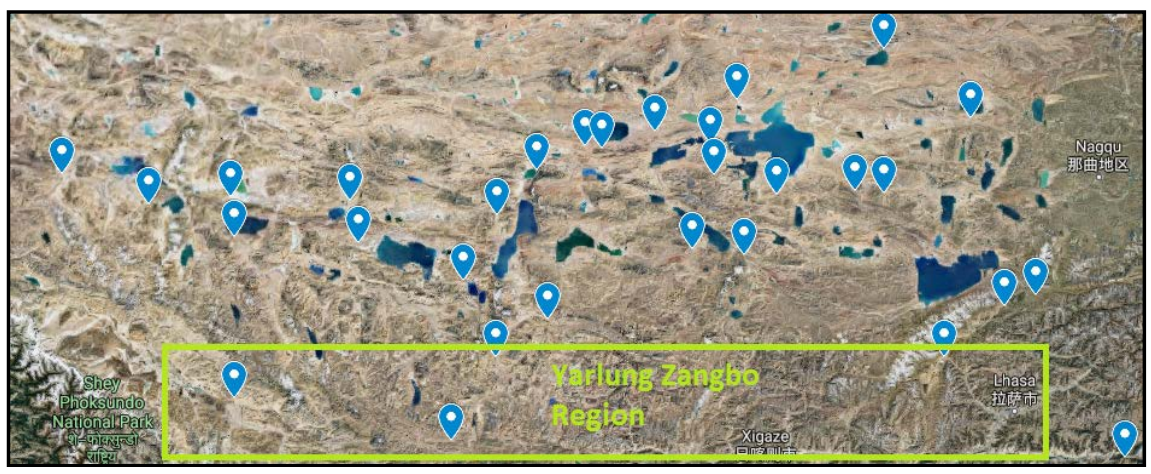

Figure 9. Industry/Placer Mine Green Box: Yarlung Zangbo Region (micro diamond finding site).

Comet Impact Features Of Libyan Desert Glass Area:

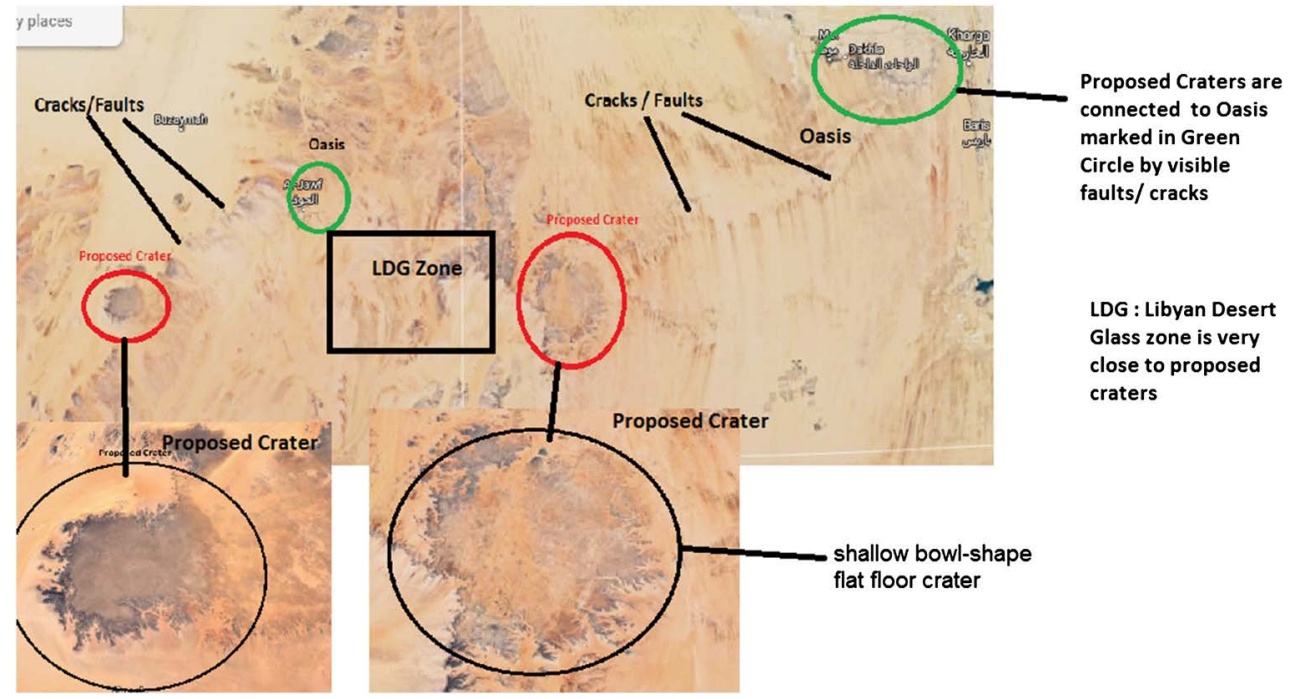

Figure 10. Possible impact craters of Egypt. 
under study for impacts and are rich with quartz, micro diamonds. Gravitational anomaly is found in large area of South Australia which is studied by A. Glikson [11] for Warburton Basin Twin Asteroid Impact, however features of the region are in line with comet impact pattern.

\section{Conclusion}

Comet entry and impact pattern is different from asteroid and is governed by multiple factors like comet composition, effects of radiation, gravitational gradient and fragmentation caused on its path. Its low density composition results in the wide, shallow bowl-shape flat floor craters and because of disintegration on its path, this unique pattern spread over large area. These craters are filled with water and have inter connectivity due to faults and fractures that are formed by impact. These impact patterns are different from rocky/metal asteroid impacts, making it difficult to trace. Hyper velocity impact of such magnitude leads to gravitational anomaly in the impact region and dusty earth material, which is thrown outward from the earth as ejecta by an impact results in tektite strewn. Due to complex composition of comet, impact regions are rich with rare findings like Osbornite, many complex alloys, various forms of quartz, UHP nitrides, carbide and microdiamonds. The lake region of Southern Tibet $82^{\circ} 30^{\prime} \mathrm{E}$ and $90^{\circ} 30^{\prime} \mathrm{E}$ and $29^{\circ} \mathrm{N}$ and $33^{\circ} \mathrm{N}$ is one such possible site and detailed study of the region will help to substantiate the findings.

\section{Acknowledgements}

We wish to thank Prof. Narendra Bhandari and Prof. Jayant Naralikar for useful discussions and guidance.

We thank

- Prof. M. S. Sisodia

- Prof. Kanchan Pande-IIT Mumbai

- Prof. Wickramsinghe

- Prof. Ranjan Gupta-Iucca

- Dr. Anil Bhardwaj-Director PRL and Mrs. Pauline-PRL

- Prof P. Sreekumar-Scientific Secretary, ISRO

This work was initiated under a able guidance of a very good person from scientific community however person has decided to stay away from the subject because of certain points about which person is sensitive.

\section{Conflicts of Interest}

The author declares no conflicts of interest regarding the publication of this paper.

\section{References}

[1] Hammel, H.B. (1995) HST Imaging of Atmospheric Phenomena Created by the Impact of Comet Shoemaker-Levy 9. Science, 267, 1288-1296. 
https://doi.org/10.1126/science.7871425

[2] Roddy, D.J. (1976) High Explosive Cratering Analogs for Bowled Shape, Central Uplift, Central Uplift, and Multiring Impact Craters. 7 th Lunar Science Conference, Houston, 15-19 March 1976, 3027-3056.

[3] Roddy, et al. (1977) Impact and Explosion Cratering. Pergamon, New York, 125-162.

[4] Fang, Q.-S., et al. (2007) Diamond and Coesite Bearing Chromitites from the Luobusa Ophiolite. Tibet Geology, 35, 875-878. https://doi.org/10.1130/G23766A.1

[5] Dobrzhinetskaya, L., et al. (2006) Diamond and Coesite after Former Stishovite in Tibet Ophiolite. American Geophysical Union, Fall Meeting 2006, Abstract ID V44B-01.

[6] Earth and Planetary Science "Earth Impact Data Base".

[7] Flynn, G.J. (2007) Physical, Chemical, and Mineralogical Properties of Comet 81P/Wild 2 Particles Collected by Stardust. Earth, Moon, and Planets, 102, 447-459. https://doi.org/10.1007/s11038-007-9214-y

[8] Sekanin (1991) Sublimation Rates of Carbon Monoxide and Carbon Dioxide from Comets at Large Heliocentric Distances. Lunar and Planetary Inst., Asteroids, Comets, Meteors, 545-548.

[9] McCall, G.J.H. (2005) Known Tektite Strewn Fields and Finds from McCall.

[10] Fazeka, A. (2013) National Geographic.

[11] Glikson, A. (2013) Evidence for Twin Asteroid Mega-Impacts, Warburton Basin N.E.S. Australia. MESA Journal, 69, 36-41.

\section{Appendix}

We express our gratitude towards the great work of Maharshi Ved Vyas.

\section{॥ इद् न मम ॥}

Meaning: "This is not Mine" or "Not my will but Thy will be done". 